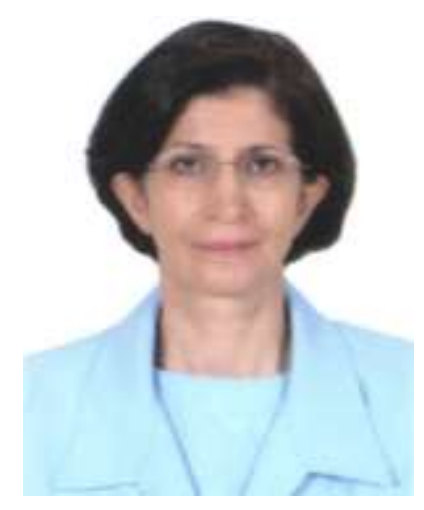

\title{
Efficient Use of Energy..... as a Life Style
}

\author{
Eng. Omneya M.K. Sabry \\ Chairperson of Executive Committee \\ Regional Center for Renewable Energy and Energy Efficiency, RCREEE \\ Cairo, Egypt \\ Email: omneya.sabry@rcreee.org
}

Since the Early Eighties of the last Century, the Egyptian Government considered Energy Conservation as one of the main pillars of Energy Planning in Egypt, based on the fact that investing in Energy Efficiency is more cost effective than in constructing new Power Plants.

Energy Efficiency (EE) Programs financed by International Financing Institutions focused at that time, on Energy Audits in Industrial Buildings, Power Plants, Electricity Transmission and in some other Governmental Buildings. Recommendations for Efficient Use of Energy and reducing energy consumption at those entities were implemented by the Use of Efficient Lamps, Improving Power Factor, Waste Heat Recovery, Thermal Insulation, Efficient Firing in Boilers.... Consequently, High Quality Energy Efficient Products were competing in the market with others not having the same advantage.

Although the above mentioned EE Programs included Awareness Campaigns for all sectors but the consumption in Residential Sector remained high and increased more and more, exceeding even the consumption in Industrial Sector specially that the prices of electricity were highly subsidized.

For that reason, more awareness campaigns (Lectures, Brochures, Audio and visual advertisement) and more incentives were offered by Ministry of Electricity and Renewable Energy (MoERE) to consumers in the Residential Sector. Meanwhile, a Program to reduce gradually subsidies on electricity prices started aiming to push consumers to follow energy efficiency instructions and buy efficient appliances especially while they were suffering from electricity cut for about two years.

To prepare for Market Transformation to efficient appliances the Government, issued the Standard Specifications and Labeling for Energy Efficient Appliances (lamps, refrigerators, freezers, washing machines, air conditioners, dish washers and others). Meanwhile, these Standards are supported with Accredited Testing Labs in National Entities (NREA,EOS,...). In addition, Ministerial decisions and resolutions were issued to enforce the standards and labeling and to monitor the industry and the market as well.

At the Regional Level the League of Arab States issued the "Arab Framework for Energy Efficiency for EndUser" supported by the Regional Center for Renewable Energy and Energy Efficiency( RCREEE) acting as technical arm.

In 2012, MoERE applied this Framework to develop its National Plan which has been endorsed by the cabinet in the same year. This Plan included EE projects to be implemented by the Ministry as well as Measures for Energy Efficiency Improvement expected as a result of implementing these projects.

Efficient Use of Energy is a Life Style and Culture that should be taught to children in Schools and at Home. 


\section{About Eng. Omneya Sabry}

\section{Qualification:}

B.Sc. Telecommunication Engineering, Faculty of Engineering, Ain Shams University, 1978

\section{Present Post:}

Chairperson of Executive Committee, Regional of Renewable Energy and Energy Efficiency

\section{Employment Record:}

2013- 2015: Vice Chairman for Studies and Technical Affairs, New and Renewable Energy Authority 2007- 2013: Undersecretary of State for International Cooperation, Ministry of Electricity and Energy 2001-2007: General Manager of Testing Department, New and Renewable Energy Authority 1986-2001: Database Developer then Computer Network Manager at IT Department, New and Renewable Energy Authority

1979- 1986: Maintenance Engineer, Arab Organization for Industrialization

Practical skills and Experience were acquired in the field of renewable energy and energy efficiency by participating in several activities including:

- Wind and solar projects

- Wind, solar and biomass studies

- Solar and biomass testing process

- Quality Management System in Testing Facilities (Solar, Biomass and Energy Efficiency)

- Standard Specifications of Solar Water heaters and PV systems

- Setting plans and securing finance for developing solar and wind systems or plants in Egypt

- National Energy Efficiency Plan for Electricity Sector, Energy Strategy of Egypt 2035.

- Research Projects in solar and biomass

- Publications in Solar, Biomass, Energy Efficiency and Leadership Development.

In addition to Three Awards of Excellence received from Minister of Electricity and Energy 